\title{
Deuterium trapping and release in JET ITER-Like Wall divertor tiles
}

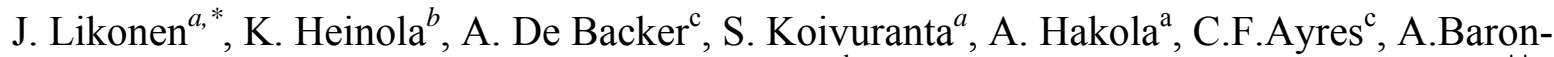 \\ Wiechec $^{c}$, P. Coad ${ }^{c}$, G. F. Matthews ${ }^{c}$, M. Mayer ${ }^{\text {d }}$, A. Widdowson ${ }^{c}$ and JET Contributors ${ }^{* *}$ \\ EUROfusion Consortium, JET, Culham Science Centre, Abingdon, OX14 3DB, UK \\ ${ }^{a}$ VTT Technical Research Centre of Finland, P.O.Box 1000, FIN-02044 VTT, Finland \\ ${ }^{b}$ University of Helsinki, P.O. Box 64, 00560 Helsinki, Finland \\ ${ }^{c}$ CCFE, Culham Science Centre, Abingdon, Oxon, OX14 3DB, UK \\ ${ }^{d}$ Max-Planck-Institut für Plasmaphysik, Garching, Germany
}

\begin{abstract}
Selected set of samples from JET-ILW divertor tiles exposed in 2011-2012 has been analysed using thermal desorption spectrometry (TDS). The highest amount of deuterium was found on the regions with the thickest deposited layers, i.e. on the High Field Gap Closure (HFGC) tile and on the apron and top part of Tile 1, which resides deep in the scrape-off layer. Outer divertor Tiles 6,7 and 8 had nearly an order of magnitude less deuterium. The remaining fractions of $\mathrm{D}$ in the analysed samples at ITER baking temperature $350{ }^{\circ} \mathrm{C}$ are rather high implying that co-deposited films may be difficult to be de-tritiated. In these cases other cleaning techniques such as oxygen discharges, laser/flash lamp heating or arcdischarge cleaning may have to be considered. Experimental TDS spectra for samples from the top horizontal and sloping parts of Tile 6 were modelled using TMAP program. Reasonable agreement between experimental and TMAP calculations was obtained.
\end{abstract}

PACS: 52.40.Hf, 52.55.Fa, 52.77.Dq, 82.80.Ms

*Corresponding author address: VTT, PO Box 1000, FI-02044 VTT, Finland.

*Corresponding author E-mail: jari.likonen@vtt.fi

Presenting author: Jari Likonen

${ }^{* * *}$ See the Appendix of F. Romanelli et al., Proceedings of the 25th IAEA Fusion Energy Conference 2014, Saint Petersburg, Russia 


\section{Introduction}

Erosion of the main chamber Be wall by hydrogen isotopes and other impurities leads to migration and deposition of Be together with hydrogen isotopes on the same or different area. The resulting co-deposited layers will be the driving mechanism behind the accumulation of in-vessel tritium inventory in ITER. Regular periods of baking of the first wall and divertor at 240 and $350{ }^{\circ} \mathrm{C}$ will be implemented in ITER in order to keep the accumulation of tritium below the administrative safety limit of $700 \mathrm{~g}$. Fuel retention has thus a key role in economical and safe operation of a fusion device.

During the shutdown in 2009-2011 all the carbon-based plasma-facing components were replaced with the ITER-like wall (JET-ILW) [1]. For the JET-ILW, divertor comprises of $\mathrm{W}$-coated carbon fibre composites (CFC) and load bearing tiles made of solid $\mathrm{W}$. The main chamber is made of solid Be except for tiles not in direct plasma contact; they consist of Becoated Inconel and W-coated CFC. Gas balance and post-mortem measurements at JET have shown a factor of 10-20 reduction in the long term fuel retention resulting from the change of wall material from carbon (JET-C) to the JET-ILW material combination [2,3]. Post-mortem analysis using the combination of various ion beam techniques (IBA), secondary ion mass spectrometry (SIMS) and thermal desorption spectrometry (TDS) gives a more accurate picture on both the total retained fuel amounts and its distribution in the torus. The present work continues the retention studies by analysing JET divertor tiles removed from the vessel after the 2011-2012 experimental campaign using TDS technique.

\section{Experimental methods}

The first JET-ILW campaigns in 2011-2012 were run with 19 hours of plasma corresponding to about 3500 pulses. Performance was gradually expanded with commissioning phases and a programme of combined scenario development with a strong 
focus on ITER critical plasma-wall interaction issues. During the last two weeks of operations in July 2012, identical H-mode plasmas in deuterium were executed with the aim to study material migration and fuel retention under typical H-mode plasma conditions. In order to accumulate a significant divertor fluence of $5.25 \times 10^{26} \mathrm{Dm}^{-2}, 151$ identical discharges $\left(\mathrm{B}_{\mathrm{t}}=\right.$ 2.0 T, $\left.\mathrm{I}_{\mathrm{p}}=2.0 \mathrm{MA}, \mathrm{P}_{\mathrm{aux}}=12 \mathrm{MW}\right)$ were executed.

The D concentrations were determined from a set of divertor tiles with a structure of CFC (bulk)/Mo $(3 \mu \mathrm{m}) / \mathrm{W}(12 \mu \mathrm{m}) / \mathrm{Mo}(4 \mu \mathrm{m}) / \mathrm{W}(4 \mu \mathrm{m})$, except Tile 3 which had the Mo layer as the plasma-facing coating. The bulk $\mathrm{W}$ tile 5 was, however, not available. TDS manufactured by Hiden Analytical Ltd (TPD Workstation type 640100) was applied to a selected number of cored divertor tile samples (see Fig. 1) with a thickness of typically $1 \mathrm{~mm}$. The details of the TPD system are reported in a companion paper [4]. Two discs were cut from the core samples and the D amounts in both discs were determined separately. The resulted TDS depth profile represents depths of 0 to $1 \mathrm{~mm}$ (W-coated sample) and $1.5 \mathrm{~mm}$ to $2.5 \mathrm{~mm}$ (bulk CFC sample). The offset of $0.5 \mathrm{~mm}$ is due to the thickness of the saw blade. TDS analyses were made in an ultra-high vacuum (UHV) system with a base pressure of $\sim 10^{-}$

${ }^{9}$ mbar. The samples were annealed with a linear ramp rate $(10 \mathrm{~K} / \mathrm{min})$ from room temperature (RT) up to $1000{ }^{\circ} \mathrm{C}$. The released gases were measured with a line-of-sight quadrupole mass spectrometer as a function of time and annealing temperature. The TDS data was collected for mass-to-charge ratios corresponding to various molecules, e.g. $\mathrm{H}_{2}, \mathrm{HD}, \mathrm{D}_{2}, \mathrm{DT}, \mathrm{T}_{2}$ and $\mathrm{Be}$. The D signal was calibrated with an ion implanted D reference sample [5].

\section{Results and discussion}

A selection of 34 samples cut from the divertor tiles exposed in 2011-2012 has been analyzed with TDS. The tiles from which the samples were cut are: 14ING1C, 14ING3B, 
14BNG4D, 2BNG6C, 2ONG7A and 2ONG8B. In the following we simply omit the full tile code and use Tile 1 for 14ING1C, Tile 3 for 14ING3B etc. Figure 2 shows TDS spectra for $\mathrm{HD}, \mathrm{D}_{2}, \mathrm{~T}_{2}$ and Be together with the sample temperature from the apron of Tile 1 (sample 12) which has a Be co-deposited layer with $\mathrm{C}$ and $\mathrm{O}$ impurities in the range of $\sim 10^{19}$ at. $/ \mathrm{cm}^{2}$ (see Table 1). The thickness of the co-deposited layer is $\sim 10 \mu \mathrm{m}$. Desorption of HD and $\mathrm{D}_{2}$ starts at $\sim 90^{\circ} \mathrm{C}$ whereas $\mathrm{T}_{2}$ and $\mathrm{Be}$ release starts at higher temperatures. The total $\mathrm{D}$ amount $(1.3 \mathrm{x}$ $10^{19}$ at. $/ \mathrm{cm}^{2}$ ) is obtained by integrating over the $\mathrm{HD}$ and $\mathrm{D}_{2}$ signals and using the calibration factor determined with the ion implanted reference sample. The $\mathrm{D}_{2}$ signal has been deconvoluted using Origin software. The first peak in Fig. 2 at $\sim 2000 \mathrm{~s}$ has been fitted with two components (peak temperatures at 328 and $418{ }^{\circ} \mathrm{C}$, respectively) and the second peak at $\sim 4000$ s with one component (peak temperature at $552{ }^{\circ} \mathrm{C}$ ) which are indicative of release from traps. The peak positions have been compared with $\mathrm{Be}$ and $\mathrm{C}$ amounts measured with IBA techniques [6] but no correlations between the peak positions and $\mathrm{Be}$ and $\mathrm{C}$ amounts have been observed whereas in Ref. [7] the peak positions were observed to shift to higher temperatures as a function of the Be amount. Deuterium is not desorbed only as a $\mathrm{D}_{2}$ molecule but there is a significant release $(\sim 19 \%$ of the total $\mathrm{D}$ atoms released $)$ of $\mathrm{HD}$ molecules at mass 3 . In addition, the shape of the HD signal is similar to that of the $\mathrm{D}_{2}$ signal. $\mathrm{H}$ in HD molecule is mainly due to hydrogen in the vacuum of the TDS system because a test measurement of a clean bulk W sample indicated that the hydrogen background signal is high. In addition, the JET samples contain hydrogen and typically there is a small $\mathrm{H}_{2}$ peak above the background level in the $\mathrm{H}_{2}$ signal. Some test measurements were also made, and $\mathrm{D}_{2} \mathrm{O}$ and CD signals were followed during the annealing. The CD signal (mass 14) contains also doubly charged $\mathrm{N}_{2}$ ions which is not possible to separate from $\mathrm{CD}$ ion. The results indicate that these signals are about two orders of magnitude smaller than $\mathrm{D}_{2}$ signal so these signals do not contain $\mathrm{D}$ in significant amounts. Figure 2 includes also the release of $\mathrm{T}_{2}$ molecules. $\mathrm{T}_{2}$ 
desorption starts at $\sim 150{ }^{\circ} \mathrm{C}$ so somewhat higher than the $\mathrm{D}_{2}$ release. Since there is much less $\mathrm{T}\left(\sim 5 \times 10^{14}\right.$ at. $\left./ \mathrm{cm}^{2}\right)$ when compared to $\mathrm{H}$ or $\mathrm{D}$, it could be expected that a $\mathrm{T}$ atom reaching the surface might have a higher probability of combining with a $\mathrm{H}$ or $\mathrm{D}$ atom than with a $\mathrm{T}$ atom. The TDS spectrometer does not have high enough mass resolution for separating HT molecule from $\mathrm{D}_{2}$ molecule so it is not possible to tell if there is release of HT. On the other hand, DT signal at mass 5 was not observed at all. At the moment it is not clear why there is strong HD emission but no DT release. There is a second release component for $\mathrm{T}_{2}$ at much higher temperature (at $\sim 800^{\circ} \mathrm{C}$ ). The first component represents release of $\mathrm{T}$ from loosely bound traps whereas the higher temperature component could be due to release of high energy DD generated $\mathrm{T}$ atoms that are implanted deeper into the sample. The $\mathrm{T}$ release will be discussed further in ref. [3]. Release of Be is also observed starting at $\sim 700{ }^{\circ} \mathrm{C}$, reaching a maximum and staying nearly at a constant level until heating is stopped.

The TDS spectra from samples from the plasma-facing surface of Tile 1 have only one peak at $\sim 400{ }^{\circ} \mathrm{C}$ so the second peak at $\sim 550{ }^{\circ} \mathrm{C}$ observed in the spectrum for sample 12 from the apron is missing. This could be partly due to that the Be content in the samples decreases from $5.8 \times 10^{18}$ at. $/ \mathrm{cm}^{2}$ for sample 6 to $2.1 \times 10^{18}$ at. $/ \mathrm{cm}^{2}$ for sample 1 (see Table 1). In ref. [8] deuterium desorption was investigated in various $\mathrm{W}$ coatings. The TDS spectra from plasmafacing surface of Tile 1 are quite similar to TDS spectra for CMSII W coatings in ref. [8]. Baldwin [7] has investigated D release from Be layers and he observed main release in the range on $200-240{ }^{\circ} \mathrm{C}$ depending on the thickness of the Be layer. The TDS spectra from Tile 1 do not thus resemble TDS spectra from clean Be but they are similar those for CMSII W coatings. The co-deposited layers on the JET samples and the $\mathrm{W}$ coatings contain $\mathrm{C}, \mathrm{O}$ and $\mathrm{Ni}$ impurities $[9,10]$ which may change the desorption properties. In addition, it has been observed with IBA and secondary ion mass spectrometry (SIMS) that there is D deeper in the samples so D release occurs both from Be co-deposit and W layer [11]. Bulk CFC samples 
(representing depths of 1.5 to $2.5 \mathrm{~mm}$ ) have also been measured with TDS, but the D amounts are in the range $\sim 10^{15}$ at. $/ \mathrm{cm}^{2}$ so D retention in the CFC bulk is not significant.

The top part of Tile 3 has slightly been eroded whereas there is no clear erosion or deposition at the bottom part of the tile. Almost the whole area of Tile 4 has been in the net deposition zone but the deposited layers are very thin. The D release spectra for samples from Tile 3 samples have only one desorption peak at $\sim 430{ }^{\circ} \mathrm{C}$ whereas samples from Tile 4 have two peaks at temperatures $240-270$ and $440-470{ }^{\circ} \mathrm{C}$ (see Fig. 3). It must be pointed out that the peaks at $\sim 4300 \mathrm{~s}$ in the spectra for Tiles 3 and 4 are due to technical problems with the heater so they are artefacts. One reason for the difference in the number of observed peaks could be the different coatings on Tiles 3 and 4; Tile 3 has a Mo layer whereas Tile 4 has W layer on the surface. On the other hand, the Be amounts on surface of Tiles 3 and 4 are quite different; the Be content on Tile 3 is in the range of $10^{18}$ at. $/ \mathrm{cm}^{2}$ (see Table 1) whereas there is much less Be on Tile $4\left(\sim 10^{17}\right.$ at. $\left./ \mathrm{cm}^{2}\right)$. In fact the peak positions for samples from Tile 3 are quite similar to those for samples from the plasma-facing surface of Tile 1.

TDS samples 1 and 8 from Tile 6 (see Fig. 1) are both in the shadowed region; sample 1 is shadowed by Tile 5 and sample 8 by Tile 7 . The $\mathrm{D}$ amounts of samples 1 and 8 are $7.5 \mathrm{x}$ $10^{17}$ at. $/ \mathrm{cm}^{2}$ and $1.2 \times 10^{18}$ at. $/ \mathrm{cm}^{2}$, respectively (see Table 1 ). The TDS sample 5 (D amount $1.4 \times 10^{18}$ at. $/ \mathrm{cm}^{2}$ ) located at the sloping part is the only sample from Tile 6 that has been exposed to the plasma. The outer strike point (OSP) during 2011-2012 operations has located most frequently further down on the sloping part of Tile 6 but it has been on the location of sample 5 for few hundreds of plasma seconds. Main D release from samples 1 (see Fig. 4) and 8 occurs at $\sim 280-300{ }^{\circ} \mathrm{C}$ but sample 1 has also a smaller peak at $\sim 440{ }^{\circ} \mathrm{C}$ whereas the main D desorption peak for sample 5 is at $\sim 370{ }^{\circ} \mathrm{C}$ so at somewhat higher temperatures than for samples 1 and 8 . The peak position for samples 1 and 8 does not correlate with Be amounts (see Table 1$)$ because sample 8 has clearly thicker Be film and more Be $\left(\sim 2.0 \times 10^{18}\right.$ at. $\left./ \mathrm{cm}^{2}\right)$ 
than sample $1\left(6.9 \times 10^{17}\right.$ at. $\left./ \mathrm{cm}^{2}\right)$. In Ref. [6] the peak positions were observed to shift to higher temperatures as a function of $\mathrm{Be}$ amount. Also the $\mathrm{C}$ content is higher on sample 8 than on sample 1 (see Table 1). Sample 5 has the highest Be amount $\left(\sim 5.9 \times 10^{18}\right.$ at. $\left./ \mathrm{cm}^{2}\right)$ and the C content is also higher than in other TDS samples from Tile 6 which most likely has some effect on the desorption of D (see Table 1).

Tile 7 has been in net deposition zone during the 2011-2012 operations according to the IBA analyses. OSP has been at the bottom of Tile 7 so sample 2 (D amount $6.8 \times 10^{17}$ at. $/ \mathrm{cm}^{2}$, see Table 1) has located in the strike point zone whereas sample 4 (D amount $8.9 \times 10^{17}$ at. $/ \mathrm{cm}^{2}$, see Fig. 3) located near the centre of Tile 7 has been in the scrape off layer (SOL) all the time. The TDS spectra for both samples from Tile 7 are similar and the desorption peaks of $\mathrm{D}$ for samples 2 and 4 from Tile 7 are fairly narrow the maximum being at $\sim 450{ }^{\circ} \mathrm{C}$ but there is a much smaller component at $\sim 210{ }^{\circ} \mathrm{C}$. Be and $\mathrm{C}$ amounts on both samples are in the range of $\sim 6 \times 10^{17}$ at. $/ \mathrm{cm}^{2}$ (see Table 1 ).

In the case of Tile 8 there is some deposition at the bottom of the tile that changes to small erosion towards the top of the tile. Sample 2 (D amount $6.5 \times 10^{17}$ at. $/ \mathrm{cm}^{2}$, see Table 1) from bottom of Tile 8 is located in the deposition zone whereas sample 6 (D amount $1.1 \mathrm{x}$ $10^{18}$ at. $/ \mathrm{cm}^{2}$ ) is from the erosion zone. Be and $\mathrm{C}$ amounts are, however, somewhat higher for sample 6 than for sample 2 (see Table 1). The TDS spectra for samples from Tile 8 are fairly broad with two desorption maxima located at $\sim 310$ and $463{ }^{\circ} \mathrm{C}$ for sample 2 and at $\sim 285$ and $396{ }^{\circ} \mathrm{C}$ for sample 6 (see Fig. 3), respectively. The first peak is located clearly at lower temperature than the D release peaks for samples from Tile 7.

Figure 4 shows the remaining fraction of D in samples 6 and 12 from Tile 1 and in samples 1 and 5 from Tile 6 . The remaining fractions in Tile 6 start to decrease at lower temperatures than in Tile 1. Interestingly the remaining fraction for sample 6 from Tile 1starts to decrease at higher temperature than for sample 12 from Tile 1 even though there is much 
thicker film and more Be on sample 12. The overall $\mathrm{C}$ content is also higher in sample 12 than in sample 6. Both IBA and SIMS analyses of samples 6 and 12 from Tile 1 show that the W content in the Be co-deposit increases towards the interface between the co-deposited layer and the substrate, and that there is same amount of $\mathrm{W}$ in the Be film in both samples. In the case of sample 1 and 5 from Tile 6 , the decrease tendencies below $400{ }^{\circ} \mathrm{C}$ are similar but different at higher temperatures. The remaining fractions at ITER baking temperature $350{ }^{\circ} \mathrm{C}$ are quite high for the samples in Figure 4; 73\% for sample 12 (Tile 1) and $92 \%$ for sample 12

(Tile 1). In the case of Tile 6 the remaining fractions are $\sim 60 \%$. Sugiyama [12] has investigated desorption efficiency of Be mixed with $\mathrm{C}$ or $\mathrm{W}$ and he has observed that the desorption efficiency decreases with increasing amount of $\mathrm{C}$ or $\mathrm{W}$. Our results do not agree with his results because the desorption efficiency is higher for sample 12 even though the codeposited layer has more C. Even though a constant ramp up to temperature of $1000{ }^{\circ} \mathrm{C}$ instead of the ITER baking cycle was applied in our studies the TDS results show that the efficiency of tritium removal using baking temperature $350{ }^{\circ} \mathrm{C}$ is limited. Co-deposited Be films mixed with $\mathrm{W}$ may be difficult to be de-tritiated by baking at $350{ }^{\circ} \mathrm{C}$. In these cases other cleaning techniques such as oxygen discharge, laser/flash lamp heating or arc-discharge cleaning [13] may have to be considered. Sugiyama [14] has also observed that baking will not remove efficiently tritium from the co-deposited layers grown at comparable or higher temperature than the baking temperature.

\section{TMAP calculations}

A first attempt of the modelling of desorption rates during TDS performed to JET-ILW samples has been done by using TMAP7 [15]. TMAP is a 1-D model which can include several atomic species and several $\mathrm{H}$ isotopes and which takes into account many mechanisms such as radioactive decay, dissociation and recombination rates at the surface, heat source and heat diffusion. For this work, we used a simplified model based on the properties of perfect W 
and we introduced 3 types of traps whose concentrations and trapping properties were adjusted to reproduce the TDS spectra. The D concentration in traps results from trapping and detrapping. The rate for detrapping, i.e. release rate depends on temperature as $\exp \left(-\mathrm{E}_{\mathrm{a}} / \mathrm{kT}\right)$ where $E_{a}$ is the activation energy to detrap and is the sum of the binding energy and the migration energy. As a result, the $\mathrm{D}$ diffusion in the perfect material is affected by the trapping and detrapping events. Traps 1 and 2 are set as Gaussian concentration profiles with an initial D filling of $100 \%$, while the third trap is described with a constant trap profile with a Gaussian-shaped D filling profile (see Table 2). The diffusion coefficient is $3.39 \times 10^{-8} \exp (-$ $0.26 \mathrm{eV} / \mathrm{kT}) \mathrm{m}^{2} / \mathrm{s}$ as obtained from previous DFT calculations [16]. We considered that the desorption is diffusion limited and that the surface is a simple boundary condition where the concentration is fixed by the Sieverts law. The deuterium solubility is $1.83 \times 10^{24} \mathrm{x} \mathrm{e}^{-1.04 \mathrm{eV} / \mathrm{kT}}$ $\mathrm{Pa}^{-1 / 2} \mathrm{~m}^{-3}[17]$. The modelled layer is $10 \mu \mathrm{m}$ thick and no $\mathrm{D}$ can diffuse through the back surface. Further developments of our model are ongoing. Adjustments of the D concentration profiles and binding energies have been done to reproduce two experimental TDS results. The obtained parameters are given Table 2 .

With our model, the closer to the surface the traps are, the faster the desorption rate increases when the traps start to release D atoms. Even with traps as close as a few hundreds of nm, experimentally observed fast desorption could not be reproduced. It was possible to reproduce the slowly decreasing desorption at high temperature by strong traps present up to microns from the surface. These traps can be due to impurities (e.g. C or O) or void-like porous structure of the W coating. Good agreements were obtained with a high concentration around $1-2$ at. $\%$ of trap 3. A higher concentration overestimated the $\mathrm{D}$ retention at high temperatures compared to experimental result while a lower concentration produced too fast release of D. Comparison between experimental and modelling results of the samples 1 and 5 from Tile 6, are shown on Figure 5. Reasonable agreement between experimental TDS and 
TMAP results was obtained. It must be noticed that the large D retention of sample $5, \sim 1.4$ $\times 10^{18} \mathrm{D} / \mathrm{cm}^{2}$, would impose more than 100 at. $\%$ of $\mathrm{D}$ if the trap concentration profile is narrower than $200 \mathrm{~nm}$. Considering that the $\mathrm{D}$ retention is mainly due to defects or impurities, a good agreement was found with a high concentration of traps (around 75 at.\%) and a 215 $\mathrm{nm}$ wide trap profile. Weak and strong trap energies can be compared with the results in ref. [18] where these are attributed to D release from saturated and unsaturated vacancy clusters, respectively, while trap 3 binding energy agrees with trapping property of $\mathrm{C}$ and $\mathrm{O}$ in $\mathrm{W}$ [19].

\section{Conclusions}

TDS has been used to analyse samples from W-coated CFC divertor tiles exposed in 2011-2012. The highest amount of deuterium was found on the regions with the thickest codeposited layers, i.e. on HFGC tile and on the top horizontal part and at the top of plasmafacing surface of Tile 1 . Outer divertor Tiles 6,7 and 8 had nearly an order of magnitude less deuterium. TDS results show that the efficiency of tritium removal using ITER baking temperature $350{ }^{\circ} \mathrm{C}$ is limited because the remaining fractions of $\mathrm{D}$ in the analysed samples are rather high. Experimental TDS spectra for samples from the top horizontal and sloping part of Tile 6 were modelled with TMAP program using three traps in the simulations. Reasonable agreement between experimental and TMAP calculations was obtained.

\section{Acknowledgements}

This project has received funding from Tekes - Finnish Funding Agency for Technology and Innovation - and the European Union's Horizon 2020 research and innovation programme. This work has been carried out within the framework of the EUROfusion Consortium and has received funding from the Euratom research and training programme 2014-2018 under grant agreement No 633053. Part of this work has been carried 
within the framework of the Eurofusion Enabling Research project on tritium retention in controlled and evolving microstructure. The views and opinions expressed herein do not necessarily reflect those of the European Commission. 


\section{References}

[1] Matthews G F, et al., 2011 Phys. Scr. T145 014001

[2] Brezinsek S, et al., 2013 Nucl. Fusion 53083023.

[3] Heinola K, et al., this conference.

[4] Baron-Wiechec A, et al., this conference.

[5] Heinola K, et al., 2015 J. Nucl. Mater., dx.doi.org/10.1016/j.jnucmat.2014.12.098.

[6] Krat S, et al., Nucl. Fusion, to be published.

[7] Baldwin M J and Doerner R P, 2014, Nucl. Fusion 54083032.

[8] Ogorodnikova O, et al., 2011, J. Nucl. Mater. 419194.

[9] Widdowson A, et al., 2014, Phys. Scr. T159 014010.

[10] Ruset C, et al., 2009, Fus. Eng. and Design 841662.

[11] Bergsåker $\mathrm{H}$, et al., this conference.

[12]Sugiyama K, et al., 2011, J. Nucl. Mater. 415 S731.

[13] Hakola A, et al., 2015, Fus. Eng. Design, dx.doi.org/10.1016/j.fusengdes.2014.12.003

[14] Sugiyama K, et al., 2013, J. Nucl. Mater. 438 S1113.

[15] Longhurst G, 2008, TMAP7 User Manual, INEEL/EXT-04-02352, Rev. 2, Idaho

National Engineering and Environment Laboratory, Idaho Falls, Idaho.

[16] Heinola K and Ahlgren T, 2010, J. of Appl. Phys. 107113531.

[17] Skinner C H, et al., 2008, Fus. Sci. Technol. 54891.

[18] Ahlgren T, et al., 2012, J. of Nucl. Mater. 427152.

[19] Heinola K, Ahlgren T, 2013, J. of Nucl. Mater. 438 S1001. 
Table 1. Composition of the surface layers on the TDS samples measured with ion beam techniques. D amount measured with TDS is also given.

\begin{tabular}{|c|c|c|c|c|c|}
\hline sample & $D_{2}\left(10^{15} \mathrm{~cm}^{-2}\right)$ & $\mathrm{O}\left(10^{15} \mathrm{~cm}^{-2}\right)$ & $\operatorname{Be}\left(10^{15} \mathrm{~cm}^{-2}\right)$ & $C\left(10^{15} \mathrm{~cm}^{-2}\right)$ & $\begin{array}{l}D_{2}\left(10^{15} \mathrm{~cm}^{-2}\right), \\
\text { TDS }\end{array}$ \\
\hline $1 / 12$ & 9450 & 13800 & 105000 & 23800 & 12600 \\
\hline $1 / 6$ & 1240 & - & 5810 & 4000 & 2940 \\
\hline $1 / 3$ & 1000 & 1620 & 4120 & 3500 & 1970 \\
\hline $1 / 1$ & 850 & - & 2070 & 1000 & 13 \\
\hline $3 / 8$ & 680 & - & 4790 & 4750 & 2800 \\
\hline $3 / 5$ & 370 & - & 1080 & 1200 & 980 \\
\hline $3 / 1$ & 680 & - & 1800 & 1650 & 1530 \\
\hline $4 / 4$ & 350 & - & 570 & 900 & 720 \\
\hline $4 / 3$ & 330 & - & 390 & 650 & 630 \\
\hline $6 / 1$ & 260 & - & 690 & 510 & 750 \\
\hline $6 / 5$ & 1130 & - & 5890 & 3900 & 1440 \\
\hline $6 / 8$ & 500 & - & 2040 & 1130 & 1170 \\
\hline $7 / 2$ & 190 & - & 520 & 700 & 680 \\
\hline $7 / 4$ & 240 & - & 490 & 590 & 890 \\
\hline $8 / 2$ & 130 & - & 90 & 250 & 650 \\
\hline $8 / 6$ & 240 & - & 180 & 390 & 1140 \\
\hline
\end{tabular}


Table 2. Parameters for the concentration, filling and trapping energies of traps obtained by fitting of the experimental results for Tile 6 . The concentration profiles for trap 1 and 2 are Gaussian $\mathrm{C}_{\mathrm{t} 0}{ }^{\mathrm{i}} \exp \left(-\mathrm{z}^{2} / \mathrm{w}^{2}\right)$ whereas trap 3 has a constant concentration $\mathrm{C}_{\mathrm{t} 0}{ }^{\mathrm{i}}$ but filling profile of $\mathrm{D}$ is a Gaussian. $\mathrm{Z}$ is the depth and $\mathrm{w}$ the width of the Gaussian profile.

\begin{tabular}{|l|l|l|l|l|}
\hline sample & & Trap 1 & Trap 2 & Trap 3 \\
\hline $6 / 5$ & $\mathrm{C}_{\mathrm{t} 0}{ }^{\mathrm{i}}($ at. \%) & 18.3 & 75.5 & 0.9 \\
\cline { 2 - 5 } & $\mathrm{w}(\mathrm{nm})$ & 215 & 215 & 2500 \\
\cline { 2 - 5 } & $\mathrm{E}_{\mathrm{a}}{ }^{\mathrm{i}}(\mathrm{eV})$ & 0.97 & 1.25 & 1.51 \\
\hline 6 & $\mathrm{C}_{\mathrm{t} 0}{ }^{\mathrm{i}}($ at. \%) & 9.2 & 4.0 & 2 \\
\cline { 2 - 5 } & $\mathrm{w}(\mathrm{nm})$ & 680 & 680 & 680 \\
\cline { 2 - 5 } & $\mathrm{E}_{\mathrm{a}}{ }^{\mathrm{i}}(\mathrm{eV})$ & 0.99 & 1.16 & 1.46 \\
\hline
\end{tabular}




\section{Figure captions}

Figure 1. A cross section of the JET divertor with a typical plasma geometry used predominantly during the JET-ILW operations, analyzed samples and tile numbering.

Figure 2. TDS spectra and annealing temperature as a function of time for sample 1/12.

Figure 3. TDS spectra of $\mathrm{D}_{2}$ for samples from Tiles 3, 4, 7 and 8 .

Figure 4. Remaining fraction of D in samples 6 and 12 from Tile 1 and in samples 1 and 5 from Tile 6. Vertical line shows the baking temperature $\left(350{ }^{\circ} \mathrm{C}\right)$ for the ITER divertor.

Figure 5. Experimental TDS results compared with calculations using TMAP after fitting of the parameters describing the traps. The insert shows the trap concentration as a function of depth. 


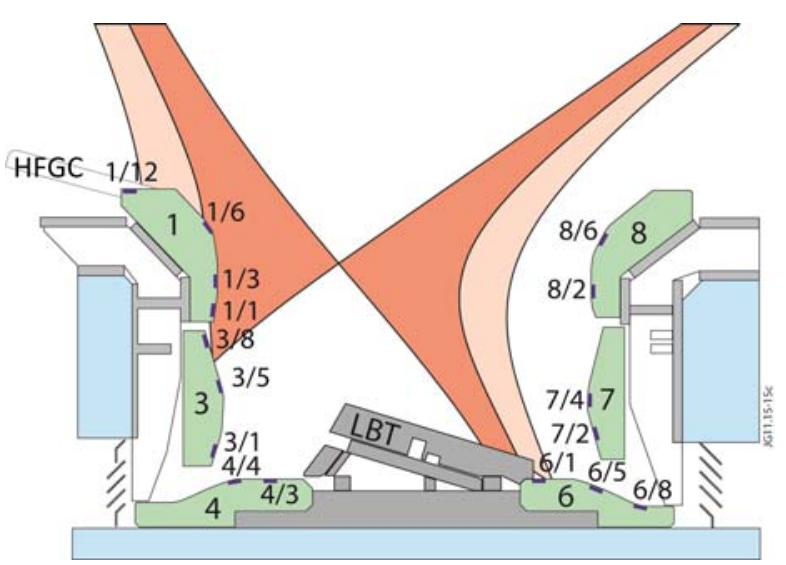

Figure 1 


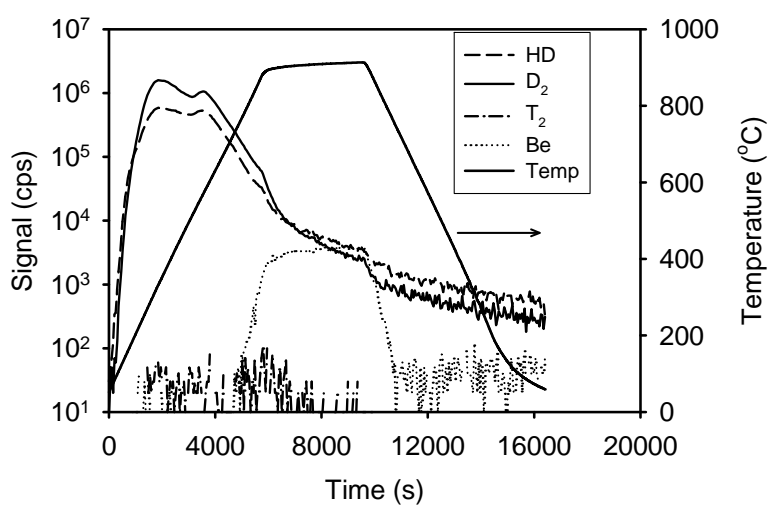

Figure 2. 


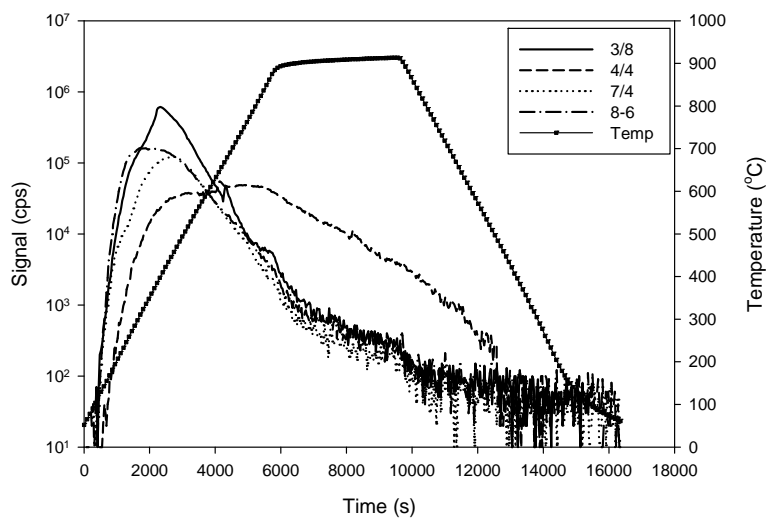

Figure 3 


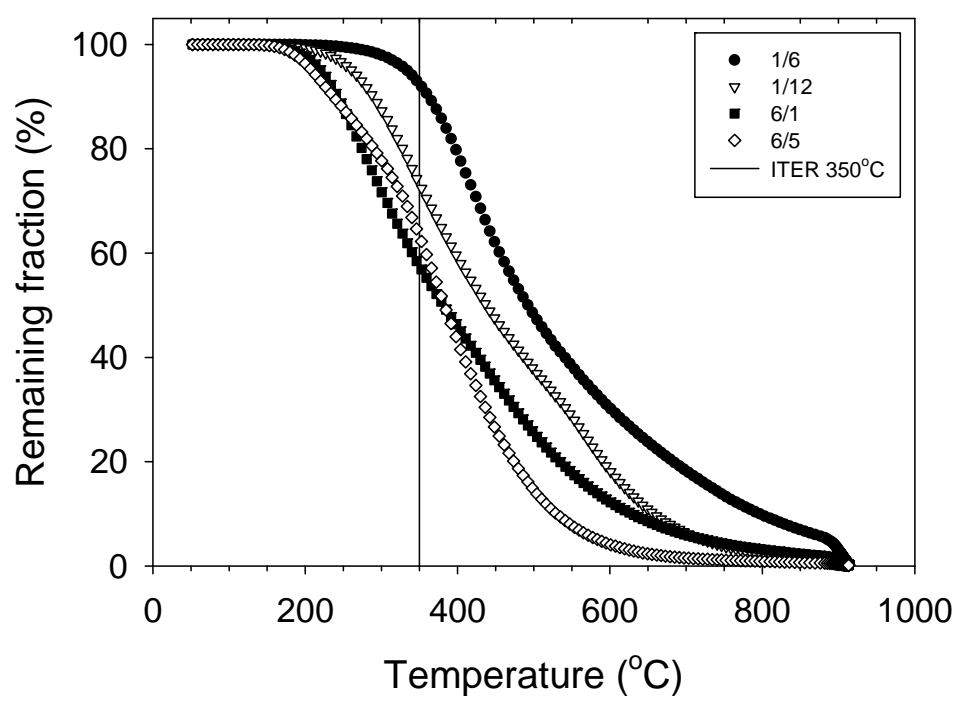

Figure 4. 


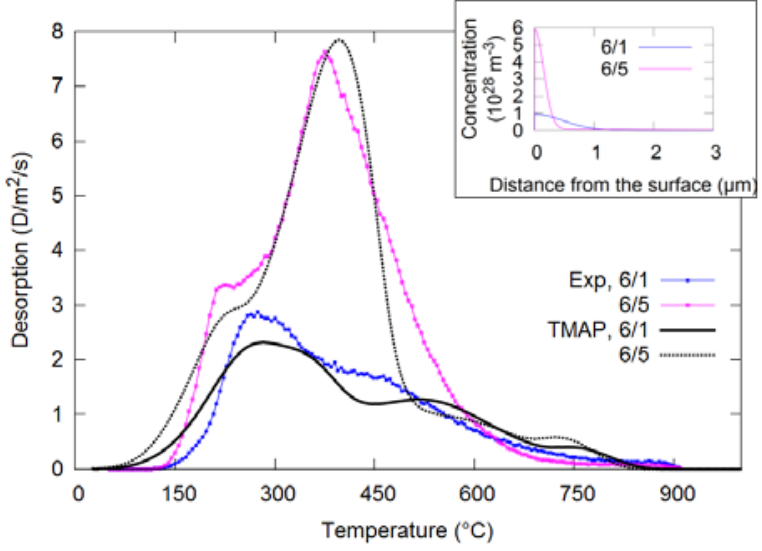

Figure 5. 